\title{
OS MANDAMENTOS
}

RUY RODRIGO BRASILEIRO DE AZAMBUJA*

Aqui se reunem homens que olham para a frente, que vislumbram os caminhos do futuro. Logo, homens que crêem. Que esperam. Que confiam no próprio esforço. Homens que plantam, não indagando se vão ou não colher pessoalmente, mas sabendo que a colheita terá sua hora e que será abundante, na medida de nosso trabalho no presente.

Aqui se reunem homens que crêem no Direito. Que esperam na Justiça.

Se há uma crise do Direito e da Justiça, sabem que o Direito positivo, o Direito aplicado, o Direito discutido e decidido, nos e pelos Tribunais, depende dos juristas, dos Juízes, dos advogados e dos promotores, de seu preparo científico, cultural e ético.

Quando os profissionais do Direito e da Lei se reunem para estudo e aperfeiçoamento, a fim de que o Direito seja, cada vez mais, aquele que deve ser, e não apenas o que é, e para que a Justiça seja, cada vez mais, a consagração do justo, estão mianifestando um ato de fé. Fé no Direito e na Justiça.

E, em assim procedendo, os que promovem este encontro, os juristas, que aqui se reunem demonstram estar conscientes de sua responsabilidade social e profissional, e patenteiam uma atitude não só de vigilância, mas sobretudo de presença, de atuação viva e responsável, numa história dirigida pelo idealismo, que é sempre desinteressado, na busca do aperfeiçoamento das instituições, das estruturas jurídicas do País, pela prevalência do Direito.

Isto aqui se faz no ano do Sesquicentenário da criação dos

* Vice-Presidente do Instituto dos Advogados do Rio Grande do Sul e antigo Conselheiro da Ordem dos Advogados do Brasil - Secção do Rio Grande do Sul. 
Cursos Jurídicos no País, em São Paulo e Olinda, fato de tanta repercussão na vida de nossa Pátria e que se deve, sobretudo, ao Visconde de São Leopoldo, José Fernandes Pinheiro, primeiro presidente da Província de São Pedro do Rio Grande do Sul, de extraordinária atuação cultural, política, parlamentar, administrativa e diplomática, em seu tempo, pelo que a Nação Ihe será sempre devedora.

Louvores à Subsecção da $\mathrm{OAB}$ de São Gabriel, por esta feliz iniciativa, de trazer aqui mestres em vários ramos do $\mathrm{Di}$ reito, que nestes dias se farão ouvir, em lições que ficarão enriquecendo e fecundando os espíritos ávidos de saber, de aperfeiçoamento, para melhor servir e para elevar o valor e o bom nome da classe.

Bem haja São Gabriel, de tantas tradições incorporadas à nossa história. Terra dos Marechais, de Hermes da Fonseca, dos Menna Barreto e de Mascarenhas de Morais. João de Deus Menna Barreto, primeiro Barão e Visconde de São Gabriel, que esteve à frente do exército pacificador da Banda Oriental, que foi governador de armas e da província, que comandou as forças que guarneciam as fronteiras sulinas durante a campanha da Cisplatina. Depois, o segundo Barão, João Propício de Figueiredo Menna Barreto que, embora nascido em Rio Pardo (1808), aqui faleceu (1867). Participou da batalha de Passo do Rosário, da revolução farroupilha, como legalista. Exerceu o comando das armas da Província e o comando-chefe do exército brasileiro em operações no Uruguai. Comandou o assalto por terra a Paissandú (1865), e dirigiu as operações que culminaram com a rendição de Montevidéu (20.2.65). Esta sepa de Menna Barreto continuou e continua, ainda hoje, as tradições de serviço à Patria. Impõese que lembremos também o Mal. João Nepomuceno Medeiros Mallet, que participou da Guerra do Paraguai e foi colaborador de Caxias. Mais recente é a figura do Marechal João Batista Mascarenhas de Morais, que comandou nossa gloriosa Força Expedicionária, em campos da Europa, contra o Nazi-Facismo.

E quem não admira a figura e a atuação do gabrielense José Plácido de Castro, herói do Acre, e que alargou nossas fronteiras?

Bem haja São Gabriel, berço de um Leonel Franca, eminente filósofo e grande apóstolo cristão da inteligência brasileira e fundador da PUC do Rio de Janeiro. Berço tambérn de Assis Brasil, nome brilhante na história do Rio Grande do Sul e do Brasil. E ainda de Alcides Maya, da Academia Brasileira de Le- 
tras, autor de "Ruínas Vivas" e de "Tapera". E porque não lembrar Fernando Abbott, político e médico humanitário? Porque não lembrar os saudosos colegas Djalma Silveira (primeiro presidente da Subsecção da OAB local) e Sílvio Faria Corrêa, figuras singulares de advogados representativos da classe?

Bem haja esta terra, que bebeu o sangue de Sepé Tiarajú, o nosso popular São Sepé, e que, nos tempos missionários, nos albores de nossa formação política e administrativa, com sentimento patriótico, gritou: "Esta terra tem dono!"

Sim! Esta terra tem dono, esta terra é nossa, porque nossos antepassados, nossos heróis a defenderam, e nô-la legaram. Esta terra é nossa! É Rio Grande, é Brasil!

Por ela somos responsáveis. Por seu destino e grandeza. Por suas instituições. E tudo para seu povo, de hoje e de amanhã.

O Brasil sempre foi marcado, em sua vida política e administrativa, desde o seu alvorecer, pelo Direito.

A influência e o culto do Direito se fizeram sentir também no Rio Grande, apesar de nossa constante mobilização em defesa das fronteiras, de nossas lutas, escaramuças e tropelias, que tinham sempre como motivo fundamental a defesa ou a reivindicação de direitos.

Hoje, quando, apesar do progresso, da tecnologia, os valores jurídicos são relegados tantas vezes, importa que se convoquem, para uma cruzada, os juristas, os advogados, os magistrados, os bacharéis, para que não deixem desaparecer de nossa vida política, administrativa e social, a força regeneradora, pacificadora e humanizante do Direito.

E o mundo que se transforma, em que se multiplicam os problemas, exige que os bacharéis aceitem o desafio que é lançado às gerações do presente, pelo estudo, o trabalho desinteressado, a generosidade do servir, a busca incessante do bem comum, certos de que o que fazemos em benefício de todos, fazemos em favor de cada um.

Sobre o Direito e os problemas da Lei, aqui vão falar grandes mestres.

Pedimos vênia para apontar, rapidamente, algumas qualidades, e certos deveres daqueles que representam, na vivência 
do Direito e na procura da Justiça, a parte humana ou profissional, indispensável e vital.

Essas qualidades e esses deveres, têm sido fixados, no tempo e no espaço, em forma de mandamentos, de decálogos. gado.

Há mandamentos do Juiz, do Promotor de Justiça, e do Advo-

\section{O JUIZ}

Diz Carnelutti: "No mais alto da escala está o Juiz. Não existe um ofício mais elevado que o seu nem uma dignidade mais imponente". E ainda: "Os Juízes são como os que pertencem a uma ordem religiosa. Cada um deles tem que ser um exemplo de virtude, se não quer que os crentes percam a fé". (Apud RUY DE AZEVEDO SODRÉ, in "Ética Profissional e o Estatuto do Advogado", Ed. Ltr, p. 131).

Enunciamos, sem os comentários, os Mandamentos do Juiz, publicados por Juan Carlos Mendonza, do Tribunal de Apelação Civil e Comercial de Assunção, Paraguai, e Professor de Direito Processual Civil e Comercial da Universidade Católica de Assunção, publicados na Revista Del Colegio de Abogados de La Plata, Ano Vill, n. ${ }^{\circ} 15$ - julo-dezembro de 1965, p. 147:

$$
\begin{aligned}
& \text { I - SÊ HONESTO } \\
& \text { II - SE SÓBRIO } \\
& \text { III - SE PACIENTE } \\
& \text { IV - SÊ TRABALHADOR } \\
& \text { V - SE IMPARCIAL } \\
& \text { VI - SÊ RESPEITOSO } \\
& \text { VII - SE JUSTO } \\
& \text { VIII - AMA O DIREITO } \\
& \text { IX - SE INDEPENDENTE } \\
& \text { X - DEFENDE A LIBERDADE. }
\end{aligned}
$$

Cada vez mais, é necessária a ciência, o saber, a cultura, a técnica. Mas, não poderá jamais ser esquecida a educação em seu sentido mais abrangente. Todos os homens, em sua formação, que começa na família, passando pela escola e continuando na sociedade, cada vez mais infestada, precisam ser conduzidos ao tipo do homem ideal: cordial, fraterno, moralizado, generoso. O homem, não lobo do homem, mas o homem irmão do homem.

Dir-se-á que isto nada tem com o Direito. 
Diremos, no entanto, que o Direito só se preocupa e só procura servir o homem ideal, que Deus criou, como Deus criou. Toda a legislação preventiva, repressiva, punitiva, contra os desmandos, contra os transgressores das leis - e os transgressores da lei são, antes, transgressores da própria natureza humana - procura defender o homem ideal. Não fora a queda original, todos os homens seriam perfeitos. Se a perfeição humana integral não é atingível, pode ser buscada sempre, perseguindo o modelo.

"Sede perfeitos, como o Pai é perfeito", lê-se nas letras sagradas.

A perfeição é, pois, uma meta.

Meta que Deus mesmo propõe aos homens.

Meta que todos os profissionais devem perseguir, para que, quanto possível, sejam perfeitos. Para que sejam advogados perfeitos, juízes perfeitos, promotores perfeitos, serventuários perfeitos, considerando o campo do Direito, da Justiça.

Difícil? Impossível? Inatingível?

Seja como for, sempre uma meta!

\section{O PROMOTOR DE JUSTIÇA}

No II Congresso Interamericano do Minstério Público, realizado em Havana, em 1956, a delegação brasileira apresentou o Decálogo do Promotor, de autoria de J.A.Cesar Salgado, e que foi aprovado e proclamado como a "Carta de Princípios do Ministério Público". Ei-lo:

I - Ama a Deus acima de tudo e vê no homem, mesmo desfigurado pelo crime, uma criatura à imagem e semelhança do criador.

II - Sê digno de tua grave missão. Lembra-te de que falas em nome da lei, da justiça e da sociedade.

III - Sô probo. Faze de tua consciência profissional um escudo invulnerável às paixões e aos interesses.

IV - Sê sincero. Procura a verdade e confessa-a-, em qualquer circunstância.

V - Sê justo. Que teu parecer dê a cada um o que é seu. 
VI - Sê nobre. Não convertas a desgraça alheia em pedestal para teus êxitos e cartaz para a tua vaidade.

VII - Sê bravo. Arrosta os perigos com destemor, sempre que tiveres um dever a cumprir, venha o atentado de onde vier.

VIII - Sê cortês. Nunca te deixes transportar pela paixão. Conserva a dignidade e a compostura, que o decoro de tuas funções exige.

IX - Sê leal. Não macules tuas ações com o emprego de meios condenados pela ética dos homens de honra.

$X$ - Sê independente. Não te curves a nenhum poder, nem aceites outra soberania senão a da lei.

\section{O ADVOGADO}

É o advogado, porém, que nos toca mais de perto, mesmo porque, na vida do Direito, na cena judiciária, é a classe mais numerosa, e, por isso mesmo, mais sujeita a percalços.

Deixamos de lado as prescrições de São Luiz de França, de Santo Ivo, de Santo Afonso de Liguori, sobre o exercício da advocacia e os deveres do advogado, para só expor os Mandamentos do Advogado, de Eduardo Couture. Para o grande processualista uruguaio, os decálogos "aspiram a dizer em poucas palavras a hierarquia do ministério do advogado. Ordenam e confrontam ao mesmo tempo; mantém alerta a consciência do dever; procuram ajustar a condição humana do advogado, dentro da missão quase divina da defesa".

São os seguintes os Mandamentos do Advogado, que nos deixou Couture:

1 - ESTUDA - O direito se transforma constantemente. Se não segues seus passos, serás cada dia um pouco menos advogado.

II - PENSA - O direito se aprende estudando, mas se exerce pensando.

III - TRABALHA - A advocacia é uma árdua fadiga posta ao serviço da Justiça.

IV - LUTA - Teu dever é lutar pelo direito, mas o dia em que encontrares em conflito o direito com a justiça, luta pela justiça. 
V - SÊ LEAL - Leal para com o teu cliente, que não deves abandonar até que compreendas que é indigno de ti. Leal para com o adversário, ainda mesmo que ele seja desleal para contigo. Leal para com o Juiz, que ignora os fatos, e deve confiar no que tu dizes e que, quanto ao direito, vez por outra, deve confiar no que tu dizes.

VI - TOLERA - Tolera a verdade alheia na mesma medida em que queres que seja tolerada a tua.

VII - TEM PACIÊNCIA - O tempo se vinga das coisas que se fazem sem sua colaboração.

VIII - TEM FÉ - Tem fé no direito, como o melhor instrumento para a convivência humana; na justiça como destino normal do direito; na paz como substitutivo bondoso da justiça; e, sobretudo, tem fé na liberdade, sem a qual não há direito, nem justiça, nem paz.

IX - ESQUECE - A advocacia é uma luta de paixões. Se, em cada batalha, forem enchendo tua alma de rancor, chegará um dia em que a vida será impossível para ti. Terminado o combate, esquece, logo, tua vitória, como tua derrota.

$X$ - AMA TUA PROFISSÃO - Trata-se de considerar a advocacia de tal maneira que, no dia em que teu filho te peça conselho sobre seu destino, consideres uma honra para ti propor-Ihe que se torne advogado.

"Justiça et Labor" é o lema desta Primeira Semana de São Gabriel, a nos impulsionar à busca, pelo trabalho, do destino natural do Direito.

Esta terra farroupilha tem dono, tem dono o Brasil! É terra nossa! Sirvamo-la, pois, com valor! Disse.*

* Palestra proferida em 16.09.77, na abertura da 1.a Semana Jurídica de São Gabriel, no Rio Grande do Sul. 